\title{
Avoidant personality disorder: current insights
}

This article was published in the following Dove Press journal:
Psychology Research and Behavior Management

\section{Lisa Lampe'}

Gin S Malhi²

'Discipline of Psychiatry, University of Newcastle, Newcastle, NSW, Australia; ${ }^{2}$ Discipline of Psychiatry, University of Sydney, Sydney, NSW, Australia

Correspondence: Lisa Lampe Discipline of Psychiatry, University of Newcastle, University Drive, Callaghan, NSW 2308, Australia

Tel +6I $24033569 \mid$

Fax +6I 240335692

Email Lisa.Lampe@newcastle.edu.au

\begin{abstract}
Avoidant personality disorder (AVPD) is a relatively common disorder that is associated with significant distress, impairment, and disability. It is a chronic disorder with an early age at onset and a lifelong impact. Yet it is underrecognized and poorly studied. Little is known regarding the most effective treatment. The impetus for research into this condition has waxed and waned, possibly due to concerns regarding its distinctiveness from other disorders, especially social anxiety disorder (SAD), schizoid personality disorder, and dependent personality disorder. The prevailing paradigm subscribes to the "severity continuum hypothesis", in which AVPD is viewed essentially as a severe variant of SAD. However, areas of discontinuity have been described, and there is support for retaining AVPD as a distinct diagnostic category. Recent research has focused on the phenomenology of AVPD, factors of possible etiological significance such as early parenting experiences, attachment style, temperament, and cognitive processing. Self-concept, avoidant behavior, early attachments, and attachment style may represent points of difference from SAD that also have relevance to treatment. Additional areas of research not focused specifically on AVPD, including the literature on social cognition as it relates to attachment and personality style, report findings that are promising for future research aimed at better delineating AVPD and informing treatment.
\end{abstract}

Keywords: avoidant personality disorder, social anxiety disorder, social cognition, psychotherapy, attachment

\section{Introduction}

Avoidant personality disorder (AVPD), as conceptualized in the Diagnostic and Statistical Manual of Mental Disorders, fifth edition (DSM-5), is characterized by extensive avoidance of social interaction driven by fears of rejection and feelings of personal inadequacy. ${ }^{1}$ It has received relatively little research attention, particularly in comparison with its nearest diagnostic relative, social anxiety disorder (SAD). The reasons for this are multifactorial, but likely relate to ongoing questions in the literature regarding the legitimacy of AVPD as a distinct category of disorder, and at least in part to a more general paucity of research into personality disorders outside of Cluster B.

It was originally thought that AVPD occurred only in association with SAD; however, large community studies have since found that in these settings about two-thirds of those with AVPD consistently do not meet additional criteria for SAD. ${ }^{2-4}$ In terms of prevalence in clinical populations, there are numerous reports regarding AVPD in anxiety samples with SAD, but few in clinical samples with other diagnoses, such as depression or other personality disorders. In a study of major depression with and without personality disorder (PD), $29 \%$ of those diagnosed with AVPD met the criteria for SAD. ${ }^{5}$ In a clinical sample of patients attending day hospitals for the treatment of 
PD, $48 \%$ of those diagnosed with AVPD met the criteria for SAD. ${ }^{6}$ These studies strongly suggest that AVPD as defined by DSM-IV ${ }^{57}$ (and DSM-5, ${ }^{1}$ since no changes to the definition were made) occurs commonly in the absence of SAD. This raises the possibility that current criteria are defining a diagnostic group that is separate and potentially different from SAD, and that further research into AVPD is warranted. Treatment is a particularly neglected field, with the vast majority of controlled treatment trials focused on SAD with or without AVPD. Weinbrecht et $\mathrm{al}^{7}$ noted the inability of a proposed Cochrane Library review to find enough suitable studies for inclusion and argued for an urgent need for more research into treatment for AVPD.

\section{Aim}

This review interpreted current insights from two perspectives: summarizing key information and opinion about AVPD and presenting novel insights from a broad literature. More specifically, the authors aimed to 1) summarize information about the nature, prevalence, and burden of AVPD; 2) briefly review its status as a diagnostic entity; 3) focus on original research with the potential to give new insights into AVPD, and especially that with potential relevance to treatment; and 4) provide a synthesis of the relevant literature rather than a detailed review of individual studies.

\section{Demographic, symptom, and disability correlates of AVPD}

Prevalence estimates for AVPD cluster around 1.5\%$2.5 \%,{ }^{2,3,8-10}$ although slightly lower $\left(0.8 \%,{ }^{11} 1.2 \%{ }^{12}\right)$ and significantly higher $\left(6.6 \%,{ }^{13} 9.3 \%{ }^{14}\right)$ estimates have also been reported. Women appear at more risk for AVPD in some studies ${ }^{9,10}$ but not all, ${ }^{11,15}$ and the data regarding age of onset are too small and inconsistent to form any conclusions.

What is known about the course and stability of diagnosis of AVPD comes from four main sources: the Longitudinal Study of Personality Disorders, Collaborative Longitudinal Personality Disorders Study (CLPS), Epidemiological Catchment Area/Hopkins Epidemiology Study of Personality Disorders, and studies using data from the Norwegian Twin Registry.

The Longitudinal Study of Personality Disorders was a prospective, repeated-measures study which aimed to study stability and change of personality disorder symptoms and personality traits. Freshman college students were screened for PD, and high- and low-probability samples were selected. 250 students completed three assessment waves at yearly intervals. A stability coefficient for AVPD symptoms from Wave 1 to Wave 3 was estimated at $r=0.48 .{ }^{16}$

The CLPS is a prospective, multisite, repeated-measures study of the course and outcome of avoidant, borderline, obsessive-compulsive, and schizotypal PDs. It also aimed to study the validity of DSM-IV definitions of these PDs and compare the ability of three general models of personality to predict outcome. ${ }^{17}$ Subjects were 668 treatment-seeking adults. ${ }^{18}$ Two years after intake, $50 \%$ of those with an initial diagnosis of AVPD continued to meet criteria; after adjusting for interrater reliability, a $\kappa$ coefficient of 0.53 was estimated. ${ }^{19}$ A 12 -month remission rate of $31 \%$ was estimated. However, for those who continued to meet criteria, the level of pathology, as indicated by the proportion of criteria met between assessment points, was relatively high from baseline to 24 months $(r=0.58)$. Ten years after baseline, stability of a diagnosis of AVPD was estimated at $r=0.51 .^{20}$

A prospective, longitudinal study of twins from the Norwegian Twin Registry assessed 2,284 twins at two time points 10 years apart. Data from those with SAD and/or AVPD were selected for further examination, but due to low rates of disorder in males, the analyses were limited to 1,761 women. A similar rank-order stability coefficient to that reported in the CLPS was estimated for AVPD in this study ( $r=0.54)$. AVPD and SAD were each reported as showing moderate stability, with $69 \%$ of those with AVPD continuing to meet the criteria for the disorder. ${ }^{21}$

In the Epidemiological Catchment Area/Hopkins Epidemiology Study of Personality Disorders, a population-based sample drawn from the Epidemiological Catchment Area study received personality evaluations by psychiatrists. A total of 294 persons received two psychiatric evaluations 12-18 years apart. ${ }^{22}$ The authors regarded antisocial, avoidant, borderline, histrionic, and schizotypal disorders as showing moderate stability in individuals, with intraclass correlations ranging from 0.12 to 0.37 ( 0.17 for AVPD) and $\kappa$ coefficients ranging from 0.07 to 0.29 (0.13 for AVPD).

These studies indicate that a diagnosis of AVPD is only moderately stable. However, it should be noted that AVPD was not particularly less stable than other PDs. Rather, it has been amply demonstrated that PD is much less stable than traits or even dimensional scores for PD criteria, and this poses a problem for psychiatric nosology more generally.

Examining other aspects, community-based studies have demonstrated that compared to controls, persons with AVPD are less likely to be married or cohabiting and to be in paid work; they are likely to be less well educated and more likely to be receiving a disability payment. ${ }^{23}$ However, in the CLPS, there 
was no difference between those with AVPD and depression on relationship or employment status or level of education. ${ }^{24}$ Persons with AVPD may be more likely to report poorer physical health, more doctor visits, and greater overall mental distress, resulting in a higher level of disability and lower quality of life. ${ }^{25}$

\section{Comorbidity}

AVPD is often comorbid with depression and substance abuse, and is likely to be associated with increased odds of suicidal ideation and attempts, ${ }^{2,6,9}$ explaining, perhaps in part, why AVPD may be a significant predictor of chronic depression. ${ }^{26}$ Intriguingly, in association with dysfunctional perfectionism, AVPD has been reported to increase the risk of postpartum depression, possibly mediated by raised levels of antepartum anxiety and depression. ${ }^{27}$ In a similar vein, AVPD and obsessive-compulsive personality disorder (OCPD) are often found in association with anorexia nervosa and binge eating disorder. ${ }^{28}$

Comorbidity with other personality disorders is also common, especially within Cluster C. Possible explanations for the apparent high level of comorbidity include shared vulnerability factors, ${ }^{29}$ criterion overlap, ${ }^{30-32}$ inherent aspects of the disorder, ${ }^{33}$ and disorder severity as a risk factor. ${ }^{34}$

\section{Historical development of the AVPD construct and its inclusion in DSM}

The history of AVPD as a construct is relevant to the key issue of whether AVPD can be justified as a distinct category of disorder. Millon ${ }^{35}$ has written in detail of the historical clinical and theoretical antecedents of AVPD (pp. 298-304). He conceived the essence of AVPD as a longing to relate to others, frustrated by oversensitivity to social stimuli, and hyperreactivity to the moods and feelings of others. He described an essential self-doubt and a mistrust of others, with the anticipation of humiliation or rejection. These concerns were viewed as leading to an "active-detached" pattern of interpersonal interaction, that is, active withdrawal from, or avoidance of, social interaction, especially when critical evaluation or rejection might result. AVPD was contrasted with the "passive-detached" pattern of schizoid PD, characterized by underarousal, amotivation, insensitivity to social cues, and lack of interest in interpersonal relationships. Millon's work was instrumental in the addition of AVPD to the psychiatric nosology with DSM-III ${ }^{151}$ in 1980. It would appear that the criteria aimed to differentiate AVPD from other disorders: from schizoid PD by means of a criterion specifying a "desire for affection and acceptance"; and from SAD by precluding its diagnosis if criteria for AVPD were met.
In psychometric analyses, DSM-IV criteria for AVPD have been reported to represent a unidimensional construct. ${ }^{36,37}$ Based on data from a psychiatric outpatient sample, Hummelen et $\mathrm{al}^{36}$ concluded that the criteria had good psychometric properties and acceptable internal consistency. AVPD showed associations with schizoid, dependent, and paranoid PDs, but it was more likely than the other disorders to be a sole PD diagnosis. Overall, there appear to have been very high rates of personality comorbidity, suggesting that this sample may have had a greater symptom severity than is typical of the general population.

Discussion regarding the validity of AVPD as a category needs to be considered in the broader context of ongoing debate about the most appropriate nosology for PD. There appears to be consensus that personality characteristics are better described dimensionally. There is also general agreement that dimensional differences on a relatively small number of measureable domains or specific traits can account for all the currently described PDs, for example, the five-factor model. ${ }^{38,39}$ The CLPS demonstrated that trait-based models outperformed both categorical and dimensional DSM-IV models in predicting global and social functioning at 10 years. ${ }^{40}$ Further, it has been proposed that all psychopathology can be described by a small number of factors, although there is lively debate concerning their nature and number. Candidates include negative affectivity, internalizing/externalizing, thought disorder, and a general psychopathology factor. ${ }^{29,37,41}$ AVPD is associated with internalizing of distress, high levels of negative affectivity, behavioral inhibition and avoidance, and low levels of extraversion.

\section{Relationship to schizoid personality disorder}

Some concern was expressed about possible overlap of AVPD with schizoid personality disorder, because of its historical relationship conceptually with schizophrenia. ${ }^{42}$ However, a low correlation with DSM-III schizoid PD $\left(0.17^{43}\right)$ and negative correlations with schizoid traits ${ }^{32}$ provided reassurance that this was not the case. The research suggests that the criteria for AVPD are distinct from schizoid PD, but also points to a possible relationship with schizophrenia. For example, an increased prevalence of AVPD in the relatives of probands with schizophrenia has been reported using the UCLA schizophrenia family study data. ${ }^{44}$ This study was conducted using DSM-III-R, in which criteria for AVPD emphasized social anxiety, and thus, the findings may represent a confirmation of the association with social anxiety in schizophrenia-spectrum disorders, rather than an association 
with AVPD per se. Indeed, Jansen et $\mathrm{al}^{45}$ reported that the presence of schizotypal traits, rather than avoidant traits, differentiated SAD from panic disorder patients.

Social anhedonia may be a key element in overlap between AVPD and schizophrenia-spectrum disorders. Covariation of schizoid and avoidant traits was observed in one study, but social anhedonia was uniquely predictive of schizoid features, and high levels of internalized shame and the need to belong were predictive of avoidant features. ${ }^{46}$ In another study, increased rates of both AVPD and schizoid PD were reported among the relatives of individuals identified as being at high risk of psychosis, with the suggestion that social anhedonia is the key risk factor. ${ }^{47}$ However, it is important to note that none of the individuals in this study had psychosis: they were classified as high risk on the basis of responses to a questionnaire measure of risk. Hence, social anhedonia may increase an individual's score on a measure of risk for psychosis, but only longitudinal studies will be able to demonstrate whether this translates to an increased incidence of psychosis.

\section{Relationship to social anxiety disorder}

One important influence on research into the overlap between SAD and AVPD has been the changes in diagnostic criteria for both disorders across different versions of the DSM. Diagnoses were hierarchical in DSM-III and a diagnosis of AVPD, as a higher order condition, precluded one of SAD. Accordingly, there could be no overlap. ${ }^{48}$ Also in DSM-III$\mathrm{R}$, in defining AVPD, references to fears of rejection were removed, and criteria added around fears of embarrassment: the net result was criteria that closely approximated SAD. It was in this context that much of the early clinical research took place, most commonly in samples meeting criteria for SAD. Subsamples with and without an additional diagnosis of AVPD were compared. High rates of comorbidity with AVPD, often in $>50 \%$ of SAD samples, were reported. ${ }^{49-52}$

This research demonstrated that both SAD and AVPD were associated with similar social fears and high levels of social anxiety and social avoidance. ${ }^{53,54}$ Most studies concluded that comorbid AVPD and SAD was associated with greater symptom burden and distress, greater disability, and more functional impairment than SAD without AVPD. Further, in many studies, once the severity of SAD was statistically controlled for ${ }^{55}$, any potential differences disappeared. It was thus concluded that AVPD simply represented a more severe form of SAD, and that it could not be distinguished otherwise. This became known as the "severity continuum hypothesis", prompting many to ask whether an additional diagnosis of AVPD was meaningful. ${ }^{55}$ In a comprehensive review, Reich ${ }^{56}$ concluded that AVPD and SAD were likely one disorder with different subtypes; he noted that chronicity was a key aspect and suggested creating a subcategory of SAD which took account of the chronicity and dysfunctional level of avoidance in AVPD.

DSM-IV made some changes which moved AVPD back somewhat toward Millon's original conceptualization of the disorder, by highlighting the fears of rejection and feelings of inadequacy as a driver of avoidance. ${ }^{57}$ A number of studies based on DSM-IV criteria showed inconsistent patterns of association between measures of symptom severity and SAD and AVPD, that is, AVPD was not consistently associated with greater severity. ${ }^{6,58-64}$ A number of authors have reported differences from SAD that they regard as significant enough to warrant retaining separate categories for the disorders, including differences in genetic risk, core self-concepts, and cognitive concerns, or differences between AVPD without $\mathrm{SAD}$, and AVPD with SAD groups that they view as inconsistent with a severity continuum. ${ }^{6,9,21,25,64-67}$

Rettew $^{68}$ has argued that the current definition of AVPD (and perhaps SAD) may be too narrowly restricted to social domains. Carter and $\mathrm{Wu}^{69}$ have suggested that a multidimensional model of social anxiety may be most appropriate, and others argue for a model in which AVPD and SAD are part of a social anxiety spectrum ${ }^{13}$ or represent social anxiety phenotypes. ${ }^{67,70}$

Changes to the criteria for SAD in DSM-5 may increase the overlap once again, as a fear of rejection has been introduced into the definition of SAD. ${ }^{1}$ All versions of the DSM referred to fears of acting in a way that will be humiliating and embarrassing. Both DSM-IV ${ }^{57}$ and DSM-5 ${ }^{1}$ acknowledged the possibility that showing signs of anxiety might also result in humiliation or embarrassment. However, DSM-5 has grouped these fears under the heading of negative evaluation, and added as specific examples of this being rejected by or causing offence to others, the latter presumably to account for cultural variations such as taijin kyofusho.

\section{Relationship to dependent personality disorder}

DSM-IV attempted to link behaviors with motivations (eg, lack of confidence in personal abilities in dependent personality disorder [DPD] and fear of rejection in AVPD) in order to better characterize personality disorders and reduce overlap. Nevertheless, it was noted that both DPD and AVPD were marked by feelings of inadequacy, need for reassurance, and hypersensitivity to criticism. ${ }^{57}$ Two early studies using DSM- 
III criteria identified high rates of meeting criteria for both AVPD and DPD, ${ }^{32,71}$ although one of these suggested that overlap of DPD may be more problematic with histrionic and borderline PDs. ${ }^{71}$ However, methodological issues including the use of self-report questionnaires, heterogeneous samples, and small numbers limit conclusions from that study.

In studies based on DSM-IV criteria, factor analysis indicated that six of the criteria for AVPD loaded with three for DPD to form a factor referred to as dependency/incompetence (based on an early maladaptive schema model).${ }^{72}$ In this study, DPD also showed some overlap with borderline PD on an attachment/abandonment factor. A fear of abandonment has also been identified in AVPD, ${ }^{73}$ and two other studies reported significant correlations between AVPD and DPD symptoms, including unassertive behavior, low self-confidence with other people, and self-depreciation. ${ }^{31,74}$ However, AVPD has been reported to differ from DPD by showing social withdrawal rather than proximity seeking ${ }^{32}$ and by a stable association with alexithymia that in AVPD is independent of depression. ${ }^{33,75}$

In conclusion, these studies are consistent with the high degree of overlap generally reported between PDs in the DSM, particularly within Clusters. Within Cluster C, DPD and AVPD appear more closely related than either is to OCPD. Although studies clearly indicate that similar behaviors (such as unassertiveness) and attributes (such as low self-esteem and low self-confidence) may be observed in DPD and AVPD, the evidence supports some differentiating features (such as completely opposite behaviors in regard to social proximity). It may be relevant that most of the research has focused on symptoms and behaviors rather than motivations. For example, the unassertiveness in AVPD is described as more closely related to fears of being rejected or humiliated due to profound personal flaws, whereas in DPD it is motivated by the individual's desire to avoid being abandoned and left to fend for themselves. A qualitative research approach may help to determine the nature of differences in behavioral motivations and self-concept, to allow further consideration of whether any differences are significant enough to justify retention of distinct categories of disorder.

\section{Phenomenology}

The key cognitive features of AVPD are a sense of inferiority coupled with a fear and expectation of rejection. Behaviorally, this manifests as widespread avoidance of social interaction, the other key feature of AVPD. Research that focuses on the cognitive and behavioral phenomenology of AVPD has the potential to enable clinicians to better understand their patients and to engage them in therapy more successfully. It is also likely to lead to therapeutic advances, as has happened in other anxiety disorders. Cognitive factors that may be relevant include those involved in social and interpersonal interaction.

\section{Social cognition}

The social psychology literature has reported on a range of findings that may be of relevance to AVPD and might form the basis of novel and potentially fruitful new research approaches in AVPD.

Social cognition research focuses on constructs such as mentalization, self-other differentiation, and affect consciousness. Mentalization refers to the capacity to speculate about the underlying drivers (eg, wants, needs, intentions, and goals) of others' behaviors and emotions. ${ }^{76}$ Deficits in mentalization have been shown to be associated with lower self-esteem and poorer relational functioning. ${ }^{77}$ Affect consciousness refers to the individual's capacity to consciously be aware of, regulate, and express emotion. Some studies have suggested deficits in mentalization and theory of mind in AVPD, ${ }^{64,78}$ but it has also been noted that avoidance of awareness of emotions may also be employed as a psychological defense strategy to protect against distress, rather than reflecting a cognitive deficit. ${ }^{77-79}$ Applying this to AVPD, it would mean that the individual might protect themselves against the pain of rejection through a general avoidance of emotions. This would be consistent with the reported association between alexithymia and AVPD. ${ }^{33,75}$ However, curiously, hypersensitivity toward the emotional states of others ${ }^{80,81}$ and inhibited self-assertion, likely in an effort to avoid rejection, have also been reported. ${ }^{81}$

In a study comparing borderline personality disorder and AVPD, affect consciousness was associated with more interpersonal problems and lower self-esteem, both at baseline and the three-year follow-up. ${ }^{82,83}$ In another study, only self-monitoring of thoughts and feelings was predictive of having AVPD; however, it explained only a small proportion of the variance. ${ }^{84}$ In a similar vein, Eikenaes et $\mathrm{al}^{64}$ showed that individuals with AVPD have a more vulnerable sense of self and less self-reflectiveness.

\section{Self-concept}

A construct of "malignant self-regard" (MSR) has been described as relevant to masochistic, self-defeating, depressive, and vulnerable narcissistic personality styles. ${ }^{85}$ It has been proposed that repeated experiences of disappointing and frustrating relationships with others are attributed to the self, leading to a negative self-concept. Characteristics of those with MSR are said to include depression, shame, beliefs of personal 
inadequacy, hypersensitive self-focus, perfectionism, and difficulty expressing anger. ${ }^{86}$ In a clinical context, exploration of self-concept in individuals with AVPD has led the authors of the present review to conclude that an MSR is likely also often present in AVPD. Hence, it is of interest that when the malignant self-regard questionnaire was tested across a range of personality disorder traits, AVPD loaded highly (alongside vulnerable narcissistic PD) on one of the two factors identified, ${ }^{86}$ and this association was relevant even after controlling for depression and self-esteem. The authors of that study considered whether social anxiety and avoidance may be an important aspect of MSR. However, it is equally possible that the "sense of personal inadequacy" in AVPD is more than just low self-esteem and may have a malignant aspect.

\section{Fear of rejection}

The fear of rejection, although a central construct in AVPD, has received surprisingly little attention from researchers. However, findings in the wider literature may be of relevance to AVPD.

Howe et $\mathrm{al}^{87}$ demonstrated possible contexts in which experiences of rejection may have lasting effects on how individuals see themselves. In their research, if a participant saw rejection as a reflection of personal inadequacy or unacceptability, they were more likely to experience sustained negative impacts from perceived rejection, especially if they also believed that their personality could not be changed.

Fear of rejection may also lead to maladaptive suppression of emotional expressive behavior. Suppression of the behavioral expression of emotion occurs naturally and can be facilitative of social relationships, for example, choosing to suppress the expression of anger or sadness. However, research indicates that excessive or contextually inappropriate suppression of emotional responses may carry a number of social costs. ${ }^{88}$ Individuals may be judged as less interested in social affiliation. ${ }^{89}$ Failure to express particular types of emotion may be especially costly. Individuals in one study who failed to show amusement when this was expected as a socially appropriate response were judged as less agreeable and less extroverted; those who failed to show sadness were seen as lacking compassion. ${ }^{89}$ Gawda et al ${ }^{90}$ noted that individuals with an avoidant attachment style are more likely to use emotional suppression in close relationships. They hypothesized that emotional suppression would be more likely to be used as a strategy in situational contexts that increase fears of rejection.

This research may have particular salience to AVPD as it suggests that the behavioral strategy of suppression of emotional expression may not prevent the feared consequence of rejection, but instead might provoke it. This presents a novel potential avenue of research in AVPD that might also have specific implications for treatment.

Taken together, these studies in the field of social psychology suggest that therapy directed toward enhancing tolerance for distress related to feeling criticized or rejected, and appropriate expression of affect may be important in AVPD. It is also clear that negative self-concept is an important therapeutic target, and that it may be more complex than simply having low self-esteem. A limitation to the generalization of this research, however, is that most of it was not conducted in samples selected for AVPD, and none of the studies specifically examined for the presence or absence of SAD. This means that it is uncertain whether the findings can be regarded as specific to AVPD, as they might apply equally to SAD.

\section{Toward an understanding of etiological factors \\ Early childhood experiences}

Millon $^{35}$ and others ${ }^{91}$ considered early interactions with parents as an important etiological factor in AVPD. The likely importance of early caregiver experiences is underscored by adoption studies. Increased odds of PD in adoptees were evident in the National Epidemiological Survey on Alcohol and Related Conditions (NESARC) study, but the odds were highest, about double that of nonadoptees, for paranoid, antisocial, and avoidant PDs. ${ }^{92}$

Studies suggest that patients with AVPD are more likely to perceive parents as less affectionate, more rejecting, guilt-engendering, and less encouraging of achievement than matched controls. ${ }^{91}$ AVPD has been linked to a recalled history of neglect, abuse, overprotection, and lower care. ${ }^{93,94}$ The CLPS found relatively few differences between AVPD and other PDs on experiences of physical or emotional abuse, or caretaker emotional denial. However, there were some noteworthy differences: those with a primary diagnosis of AVPD reported fewer positive relationships with other adults and poorer parental social ability and less sexual abuse and physical neglect than a group of persons with other PDs. ${ }^{95}$ Research has also reported associations that were mediated in part by a maladaptive schema of belief in the need to subjugate personal needs, wants, and desires to avoid negative interpersonal outcomes, although overall few relationships with early maladaptive schemas were evident. ${ }^{96}$

In summary, despite some variability of findings, there seems to be reasonable support for an association between 
neglect and emotional abuse, and perhaps less encouragement by early caregivers and later AVPD symptomatology. Recall bias influenced by underlying hypersensitivity cannot be excluded as a contributor to these findings, but twin studies point to some role for environmental factors, ${ }^{21}$ and negative experiences within the family would appear a likely candidate.

\section{Attachment style}

Attachment provides an explanatory model for the link between temperament, adverse childhood environment, and PD. ${ }^{97-100}$ An attachment style variously referred to as avoidant, detached, or dismissing (also referred to as an "anxious/avoidant" style) has been proposed to contribute to the development of AVPD. This attachment style may be associated with a negative self-concept and a fear of intimate relationships. ${ }^{101}$ A fearful attachment style, described as involving a desire for intimacy in the presence of interpersonal distrust and fear of rejection, has been proposed to be of particular relevance to AVPD. Indeed, Bartholomew regarded the fearful style, when extreme, as typical of AVPD. ${ }^{102}$

A number of studies have confirmed the theorized relationship between AVPD and both anxious and avoidant strategies. ${ }^{46,81,103-110}$ Using the four-category model of Bartholomew and Horowitz, ${ }^{111}$ which posits that attachment may be classified into one of four groups determined by positive or negative views of the self and positive or negative views of others, some studies also identified a fearful attachment style in AVPD. ${ }^{101,112,113}$ In the four-category model, the fearful attachment style may be the most disabling, since it is associated with negative views of both self and other. Research suggests that experiences with critical, demeaning, and neglectful early caregivers may increase the risk of developing a fearful attachment style.

These findings are important because attachment style is highly relevant to assessment and treatment. For example, it is more difficult for a therapist to establish and maintain a relationship with an individual who is distrustful of others, who is hypersensitive to criticism and rejection, and who relies on avoidant coping strategies.

\section{Links between early childhood experiences and the core features of AVPD: hypervigilance, avoidance, low self- esteem, and negative self-concept}

It has been proposed that a child may develop hypervigilance as a coping strategy when a parent is inaccessible or inconsistent, ${ }^{91,114}$ and this hypervigilance may then generalize to other social situations. This might be expected to apply equally to SAD. Other authors suggest that repeated negative interactional experiences with parents might lead the child to expect unpleasant or distressing interactions, and to then employ avoidance as a coping strategy. ${ }^{35,114-116}$ Over time, this might become the default strategy. The resulting social isolation in turn predisposes to greater emotional distress. From a cognitive theory perspective, this would represent a cognitive mediational factor reinforcing avoidance as a coping strategy. Millon ${ }^{35}$ viewed parental rejection or denigration as a critical factor in the erosion of self-esteem in the child (p. 318).

A role for temperamental factors has also been proposed. ${ }^{117}$ Personality rigidity, hypersensitivity, high harm avoidance, low novelty-seeking, and an overactive behavioral inhibition system have been proposed as relevant factors, ${ }^{117}$ with some supportive evidence..$^{59,93,118}$ It also seems likely that SAD and AVPD share some temperamental vulnerability factors, including negative emotionality (neuroticism), behavioral inhibition, and shyness. ${ }^{117}$

Temperamental factors may act by increasing the individual's vulnerability to the effects, and possibly even the risk, of negative childhood experiences. ${ }^{91}$ They may also influence the selection of coping strategies, such as avoidance, and the adverse impact of maladaptive strategies. A relationship between attachment and temperament has also been described. For example, the amount and expression of distress an infant experiences upon separation from the early caregiver may be influenced by temperamental traits, and the responsiveness of the caregiver may influence attachment. ${ }^{100}$

A biobehavioral factor of approach/avoidance may be of particular relevance. "Onlooking" behavior, where a child watches others play but is too anxious to attempt to join them, has been described as a behavioral marker of an "approachavoidance" conflict. ${ }^{119,120}$ In this model, an avoidant child is said to be low on social approach and high on social avoidance, and may be particularly prone to AVPD. ${ }^{117}$ In one study, avoidant children differed significantly from shy, unsociable, and sociable children by scoring higher on measures of depressive symptoms, negative affect, fear of negative evaluation, and lower on positive affect and well-being. ${ }^{119}$

\section{Genetic factors}

Genetic studies have the potential to offer insight into the relative contributions of genes and environment, as well as more specifically to inform the question of diagnostic validity. A heritability coefficient for AVPD of 0.64 has been estimated in one study. ${ }^{121}$ Initial and 10-year follow-up genetic findings in AVPD and SAD using data from the Norwegian Twin Registry indicated that genetic influences on AVPD were stable 
over time, but the genetic risk for SAD was more variable.,.$^{3,21}$ The authors concluded that environmental factors contributed to co-occurrence of AVPD and SAD, but that there are potentially distinct factors underlying SAD and AVPD.

In summary, these studies suggest a complex relationship between genes, temperament, early childhood environment, attachment style, and personality in AVPD, which remains to be fully elucidated. The research indicates some shared vulnerability with $\mathrm{SAD}$, but also some points of difference.

\section{Treatment}

Apart from case reports, there is little research into the treatment of AVPD specifically. ${ }^{70,122}$ Most of the empirical research is derived from treatment studies of SAD, where outcome for SAD with and without AVPD has been reported. There are mixed findings: some studies report no effect on treatment outcome, ${ }^{123-125}$ while others report less likelihood of remission from $\mathrm{SAD}^{126}$ and failure to reach normative levels of functioning; ${ }^{127,128}$ some studies suggest an increased risk of persistent symptoms of SAD when comorbid with AVPD. ${ }^{129-131}$ There is also a report of a poorer outcome unrelated to severity of SAD symptoms. ${ }^{132}$ However, overall these studies support the value of cognitive behavioral approaches in relieving symptoms of AVPD to at least some extent.

Pharmacotherapy is generally not thought to be effective in personality disorder, and there are no trials of its use specifically in AVPD reported in the literature. However, clinical recommendations exist for using similar pharmacotherapeutic approaches as for SAD. ${ }^{133}$ In SAD, the serotonin-specific reuptake inhibitors and serotonin noradrenaline reuptake inhibitors have a robust efficacy literature, ${ }^{134-138}$ and clearly pharmacotherapy is likely to be of value for comorbidity, such as depression.

In terms of psychological treatment, graded exposure, cognitive behavior therapy (CBT), social skills training, psychodynamic psychotherapy, schema therapy, and supportiveexpressive psychotherapy have all been reported to be helpful, although the number of studies is small. ${ }^{83,91,127,139-144}$ Case reports of other psychological approaches exist (eg, Acceptance and Commitment Therapy, ${ }^{145}$ Emotion Focused Therapy, ${ }^{146}$ and Wilderness Therapy ${ }^{128}$ ) but randomized, controlled trials are lacking for these other approaches.

Case reports of successful therapy emphasized a formulation that included experiential avoidance as a key maladaptive coping strategy requiring recognition by the therapist and targeted intervention. In relevant cognitive research, a more threat-avoidant attention focus, compared to threat-focused, has been reported in association with poorer outcome in SAD and may therefore be a relevant consideration for CBT. ${ }^{147}$ The formulations in these case reports incorporated hypothesized deficits in social cognition, which were also targeted in therapy. ${ }^{146,148}$ Notable aspects of this research include the congruence with recommendations for social skills training in AVPD made by early investigators ${ }^{140,149,150}$ and the longterm (years) time frame of the therapy.

Currently, it appears that a problem-focused approach is the best basis for treatment planning. Selection of treatment strategies should be based on a comprehensive, individualized formulation that takes account of symptoms, emotional functioning (including mentalization and alexithymia), relational functioning (including attachment style), and current coping strategies (including behavioral and experiential avoidance). Development and testing of interventions which specifically target the identified symptoms and difficulties of AVPD is urgently needed. The research into social cognition appears particularly promising for AVPD and other personality disorders.

\section{Conclusion}

AVPD is a common condition associated with considerable distress and impairment. It has, for some time, been viewed as essentially a more severe variant of SAD, with criterion overlap likely exacerbating the problem. An increasing body of research is demonstrating meaningful points of difference from SAD, including attachment pathology and self-concept. A model of social anxiety in which SAD and AVPD represent different phenotypes has been proposed. The field of social psychology offers a number of insights that appear highly relevant to AVPD and may represent a fruitful avenue of further study. In particular, social cognition, including reflective functioning, theory of mind, and affect consciousness offer promise. Further research into the meaning of rejection and the nature of the sense of inferiority and personal inadequacy that is said to characterize AVPD may yield information of relevance to better delineating AVPD. In turn, this may inform changes to diagnostic criteria to better differentiate the condition. An understanding of attachment difficulties in AVPD appears especially relevant to treatment, and the literature suggests that many of the CBT strategies used for SAD are also likely to be helpful. Targeting self-concept, experiential avoidance, and maladaptive schemas may also be helpful. However, optimal treatment has yet to be empirically established. If the current structure of psychiatric classification is retained, future research studies would ideally compare groups with SAD without AVPD, AVPD without $\mathrm{SAD}$, and a comorbid group, as this will be important when 
considering the lingering issue of whether AVPD represents a distinct category of disorder. If a domain-based model of classification is adopted, an understanding of the broad symptomatology and vulnerability factors in disorders of social anxiety can inform decision-making.

\section{Disclosure}

The authors report no conflicts of interest in this work.

\section{References}

1. American Psychiatric Association. Diagnostic and Statistical Manual of Mental Disorders: DSM-5. Arlington, VA: American Psychiatric Association; 2013.

2. Cox BJ, Pagura J, Stein MB, Sareen J. The relationship between generalized social phobia and avoidant personality disorder in a national mental health survey. Depress Anxiety. 2009;26(4):354-362.

3. Reichborn-Kjennerud T, Czajkowski N, Torgersen S, et al. The relationship between avoidant personality disorder and social phobia: a population-based twin study. Am J Psychiatry. 2007;164(11):1722-1728.

4. Lampe L. Social anxiety disorders in clinical practice: differentiating social phobia from avoidant personality disorder. Australas Psychiatry. 2015;23(4):343-346.

5. Ralevski E, Sanislow CA, Grilo CM, et al. Avoidant personality disorder and social phobia: distinct enough to be separate disorders? Acta Psychiatr Scand. 2005;112(3):208-214.

6. Hummelen B, Wilberg T, Pedersen G, Karterud S. The relationship between avoidant personality disorder and social phobia. Compr Psychiatry. 2007;48(4):348-356.

7. Weinbrecht A, Schulze L, Boettcher J, Renneberg B. Avoidant personality disorder: a current review. Curr Psychiatry Rep. 2016; 18(3):29.

8. Asarnow RF, Nuechterlein KH, Fogelson D, et al. Schizophrenia and schizophrenia-spectrum personality disorders in the first-degree relatives of children with schizophrenia: The UCLA Family Study. Arch Gen Psychiatry. 2001;58(6):581-588.

9. Lampe L, Sunderland M. Social phobia and avoidant personality disorder: similar but different? J Pers Disord. 2015;29(1):115-130.

10. Grant BF, Hasin DS, Stinson FS, et al. Prevalence, correlates, and disability of personality disorders in the United States: results from the national epidemiologic survey on alcohol and related conditions. J Clin Psychiatry. 2004;65(7):948-958.

11. Coid JM, Yang MM, Tyrer PM, Roberts AP, Ullrich SP. Prevalence and correlates of personality disorder in Great Britain. Br J Psychiatry. 2006;188(5):423-431.

12. Trull TJ, Jahng S, Tomko RL, Wood PK, Sher KJ. Revised NESARC personality disorder diagnoses: gender, prevalence, and comorbidity with substance dependence disorders. J Pers Disord. 2010;24(4):412-426.

13. Tillfors M, Furmark T, Ekselius L, Fredrikson M. Social phobia and avoidant personality disorder: one spectrum disorder? Nord $J$ Psychiatry. 2004;58(2):147-152

14. Quirk SE, Berk M, Pasco JA, et al. The prevalence, age distribution and comorbidity of personality disorders in Australian women. Aust N Z J Psychiatry. 2017;51(2):141-150.

15. Lenzenweger MF, Lane MC, Loranger AW, Kessler RC. DSM-IV personality disorders in the national comorbidity survey replication. Biol Psychiatry. 2007;62(6):553-564.

16. Lenzenweger MF. Stability and change in personality disorder features: the Longitudinal Study of Personality Disorders. Arch Gen Psychiatry. 1999;56(11):1009-1015.

17. Morey LC, Skodol AE, Grilo CM, et al. Temporal coherence of criteria for four personality disorders. J Pers Disord. 2004;18: 394-398.
18. Gunderson JG, Shea T, Skodol AE, McGlashan TH. The collaborative longitudinal personality disorders study: development, aims, design, and sample characteristics. J Pers Disord. 2000;14(4):300.

19. Grilo CM, Sanislow CA, Gunderson JG, et al. Two-year stability and change of schizotypal, borderline, avoidant, and obsessive-compulsive personality disorders. J Consult Clin Psychol. 2004:427-438.

20. Hopwood CJ, Morey LC, Donnellan MB, et al. Ten-year rank-order stability of personality traits and disorders in a clinical sample. J Pers. 2013;81(3):335-344.

21. Torvik FA, Welander-Vatn A, Ystrom E, et al. Longitudinal associations between social anxiety disorder and avoidant personality disorder: A twin study. J Abnorm Psychol. 2016;125 (1):114-124.

22. Nestadt G, Di C, Samuels JF, et al. The stability of DSM personality disorders over twelve to eighteen years. J Psychiatr Res. 2010;44(1):1-7.

23. Olsson I, Dahl AA. Avoidant personality problems - their association with somatic and mental health, lifestyle, and social network. A community-based study. Compr Psychiatry. 2012;53(6):813-821.

24. Skodol AE, Gunderson JG, McGlashan TH, et al. Functional impairment in patients with schizotypal, borderline, avoidant, or obsessive-compulsive personality disorder. Am J Psychiatry. 2002;159(2):276-283.

25. Marques L, Porter E, Keshaviah A, et al. Avoidant personality disorder in individuals with generalized social anxiety disorder: what does it add? J Anxiety Disord. 2012;26(6):665-672.

26. Klein JP, Roniger A, Schweiger U, Spath C, Brodbeck J. The association of childhood trauma and personality disorders with chronic depression: a cross-sectional study in depressed outpatients. $J$ Clin Psychiatry. 2015;76(6):e794-e801.

27. Oddo-Sommerfeld S, Hain S, Louwen F, Schermelleh-Engel K. Longitudinal effects of dysfunctional perfectionism and avoidant personality style on postpartum mental disorders: pathways through antepartum depression and anxiety. J Affect Disord. 2016;191:280-288.

28. Farstad SM, McGeown LM, von Ranson KM. Eating disorders and personality, 2004-2016: a systematic review and meta-analysis. Clin Psychol Rev. 2016;46:91-105.

29. Caspi A, Houts RM, Belsky DW, et al. The p factor. Clin Psychol Sci. 2014;2(2):119-137.

30. Tyrer P, Reed GM, Crawford MJ. Classification, assessment, prevalence, and effect of personality disorder. Lancet. 2015;385(9969):717-726.

31. Rees A, Hardy GE, Barkham M. Covariance in the measurement of depression/anxiety and three Cluster $\mathrm{C}$ personality disorders (avoidant, dependent, obsessive-compulsive). J Affect Disord. 1997;45(3):143-153.

32. Trull TJ, Widiger TA, Frances A. Covariation of criteria sets for avoidant, schizoid, and dependent personality disorders. Am J Psychiatry. 1987;144(6):767-771.

33. Nicolo G, Semerari A, Lysaker PH, et al. Dependent personality disorders unlike avoidant personality disorders are not related to alexithymia after controlling for depression: a reply to Loas. Psychiatry Res. 2012;196(2-3):327-328.

34. Skodol AE, Oldham JM, Hyler SE, et al. Patterns of anxiety and personality disorder comorbidity. J Psychiat Res. 1995;29(5):361-374.

35. Millon T. Disorders of Personality DSM-III: Axis II. New York, NY: John Wiley \& Sons; 1981.

36. Hummelen B, Wilberg T, Pedersen G, Karterud S. An investigation of the validity of the Diagnostic and Statistical Manual of Mental Disorders, Fourth Edition avoidant personality disorder construct as a prototype category and the psychometric properties of the diagnostic criteria. Compr Psychiatry. 2006;47(5):376-383.

37. Bachrach N, Croon MA, Bekker MH. Factor structure of selfreported clinical disorders and personality disorders: a review of the existing literature and a factor analytical study. J Clin Psychol. 2012;68(6):645-660.

38. Saulsman LM, Page AC. The five-factor model and personality disorder empirical literature: a meta-analytic review. Clin Psychol Rev. 2004;23(8):1055-1085. 
39. Widiger TA, Costa PT. Integrating normal and abnormal personality structure: the five-factor model. J Pers. 2012;80(6):1471-1506.

40. Morey LC, Hopwood CJ, Markowitz JC, et al. Comparison of alternative models for personality disorders, II: 6-, 8- and 10-year follow-up. Psychol Med. 2012;42(8):1705-1713.

41. Clark LA. Temperament as a unifying basis for personality and psychopathology. J Abnorm Psychol. 2005;114(4):505-521.

42. Livesley WJ, West M, Tanney A. Historical comment on DSMIII schizoid and avoidant personality disorders. Am J Psychiatry. 1985;142(11):1344-1347.

43. Kass F, Skodol AE, Charles E, Spitzer RL, Williams JB. Scaled ratings of DSM-III personality disorders. Am J Psychiatry. 1985; 142(5):627-630.

44. Fogelson DL, Nuechterlein KH, Asarnow RA, et al. Avoidant personality disorder is a separable schizophrenia-spectrum personality disorder even when controlling for the presence of paranoid and schizotypal personality disorders. The UCLA family study. Schizophr Res. 2007;91(1-3):192-199.

45. Jansen MA, Arntz A, Merckelbach H, Mersch PP. Personality disorders and features in social phobia and panic disorder. J Abnorm Psychol. 1994;103(2):391-395.

46. Winarick DJ, Bornstein RF. Toward resolution of a longstanding controversy in personality disorder diagnosis: contrasting correlates of schizoid and avoidant traits. Personal Indiv Diff. 2015;79: 25-29.

47. Gooding DC, Tallent KA, Matts CW. Rates of avoidant, schizotypal, schizoid and paranoid personality disorders in psychometric high-risk groups at 5-year follow-up. Schizophr Res. 2007;94(1-3):373-374.

48. American Psychiatric Association. Diagnostic and Statistical Manual of Mental Disorders (Third Edition - Revised). Washington, DC: American Psychiatric Association; 1987.

49. Alden LE, Laposa JM, Taylor CT, Ryder AG. Avoidant personality disorder: current status and future directions. J Personal Disord. 2002;16(1):1-29.

50. Alnaes R, Torgersen S. The relationship between DSM-III symptom disorders (Axis I) and personality disorders (Axis II) in an outpatient population. Acta Psychiatr Scand. 1988;78(4):485-492.

51. Brown EJ, Heimberg RG, Juster HR. Social phobia subtype and avoidant personality disorder: effect on severity of social phobia, impairment, and outcome of cognitive behavioral treatment. Behav Ther. 1995;26:467-486.

52. Schneier FR, Spitzer RL, Gibbon M, Fyer AJ, Liebowitz MR. The relationship of social phobia subtypes and avoidant personality disorder. Compr Psychiatry. 1991;32(6):496-502.

53. Herbert JD, Hope DA, Bellack AS. Validity of the distinction between generalized social phobia and avoidant personality disorder. JAbnorm Psychol. 1992;101(2):332-339.

54. Holt CS, Heimberg RG, Hope DA. Avoidant personality disorder and the generalized subtype of social phobia. J Abnorm Psychol. 1992;101(2):318-325.

55. Chambless DL, Fydrich T, Rodebaugh TL. Generalized social phobia and avoidant personality disorder: meaningful distinction or useless duplication? Depress Anxiety. 2008;25(1):8-19.

56. Reich J. The relationship of social phobia to avoidant personality disorder: a proposal to reclassify avoidant personality disorder based on clinical empirical findings. Eur Psychiatry. 2000;15(3):151-159.

57. American Psychiatric Association. Diagnostic and Statistical Manual of Mental Disorders. 4 ed. Washington, DC: American Psychiatric Association; 1994.

58. Kose S, Solmaz M, Ceikel FC, et al. Comorbidity of avoidant personality disorder in generalized social phobia and its impact on psychopathology. Klinik Psikofarmakoloji Bulteni/Bulletin Clin Psychopharmacol. 2009;19(4):340-346.

59. Marteinsdottir I, Tillfors M, Furmark T, Anderberg UM, Ekselius L. Personality dimensions measured by the Temperament and Character Inventory (TCI) in subjects with social phobia. Nord J Psychiatry. 2003;57(1):29-35.
60. Tran GQ, Chambless DL. Psychopathology of social phobia: effects of subtype and avoidant personality disorder. J Anxiety Disord. 1995;9:489-501.

61. Turner SM, Beidel DC, Dancu CV, Keys DJ. Psychopathology of social phobia and comparison to avoidant personality disorder. J Abnorm Psychol. 1986;95(4):389-394.

62. Turner SM, Beidel DC, Townsley RM. Social phobia: a comparison of specific and generalized subtypes and avoidant personality disorder. J Abnorm Psychol. 1992;101(2):326-331.

63. van Velzen CJ, Emmelkamp PM, Scholing A. Generalized social phobia versus avoidant personality disorder: differences in psychopathology, personality traits, and social and occupational functioning. $J$ Anxiety Disord. 2000;14(4):395-411.

64. Eikenaes I, Hummelen B, Abrahamsen G, Andrea H, Wilberg T. Personality functioning in patients with avoidant personality disorder and social phobia. J Personal Disord. 2013;27(6):746-763.

65. Dreessen L, Arntz A, Hendriks T, Keune N, van den Hout M. Avoidant personality disorder and implicit schema-congruent information processing bias: a pilot study with a pragmatic inference task. Behav Res Ther. 1999;37(7):619-632.

66. Tillfors M, Ekselius L. Social phobia and avoidant personality disorder: are they separate diagnostic entities or do they reflect a spectrum of social anxiety? Isr J Psychiatry Relat Sci. 2009;46(1):25-33.

67. Carmichael KLC, Sellbom M, Liggett J, Smith A. A personality and impairment approach to examine the similarities and differences between avoidant personality disorder and social anxiety disorder. Personal Ment Health. 2016;10(4):337-347.

68. Rettew DC. Avoidant personality disorder, generalized social phobia, and shyness: putting the personality back into personality disorders. Harv Rev Psychiatry. 2000;8(6):283-297.

69. Carter SA, Wu KD. Relations among symptoms of social phobia subtypes, avoidant personality disorder, panic, and depression. Behav Ther. 2010;41(1):2-13.

70. Lampe L. Avoidant personality disorder as a social anxiety phenotype: risk factors, associations and treatment. Curr Opin Psychiatry. 2016;29(1):64-69.

71. Reich J. Avoidant and dependent personality-traits in relatives of patients with panic disorder, patients with dependent personality-disorder, and normal controls. Psychiatry Res. 1991;39(1): 89-98.

72. Gude T, Hoffart A, Hedley L, Rø Ø. The dimensionality of dependent personality disorder. J Personal Disord. 2004;18(6):604-610.

73. Eikenæs I, Pedersen G, Wilberg T. Attachment styles in patients with avoidant personality disorder compared with social phobia. Psychol Psychother. 2016;89(3):245-260.

74. Leising DD, Sporberg DD, Rehbein DD. Characteristic interpersonal behavior in dependent and avoidant personality disorder can be observed within very short interaction sequences. J Pers Disord. 2006;20(4):319-330.

75. Loas G, Baelde O, Verrier A. Relationship between alexithymia and dependent personality disorder: a dimensional analysis. Psychiatry Res. 2015;225(3):484-488.

76. Fonagy P, Luyten P. A developmental, mentalization-based approach to the understanding and treatment of borderline personality disorder. Dev Psychopathol. 2009;21(4):1355-1381.

77. Antonsen BT, Johansen MS, Ro FG, Kvarstein EH, Wilberg T. Is reflective functioning associated with clinical symptoms and longterm course in patients with personality disorders? Compr Psychiatry. 2016;64:46-58.

78. Dimaggio G, Procacci M, Nicolò G, et al. Poor metacognition in narcissistic and avoidant personality disorders: four psychotherapy patients analysed using the Metacognition Assessment Scale. Clin Psychol Psychother. 2007;14:386-401.

79. Bilotta E, Giacomantonio M, Leone L, Mancini F, Coriale G. Being alexithymic: necessity or convenience. Negative emotionality $\mathrm{x}$ avoidant coping interactions and alexithymia. Psychol Psychother. 2016;89(3):261-275. 
80. Hengartner MP, Ajdacic-Gross V, Rodgers S, Müller M, Haker H, Rössler W. Fluid intelligence and empathy in association with personality disorder trait-scores: exploring the link. Eur Arch Psychiatry Clin Neurosci. 2014;264(5):441-448.

81. Beeney JE, Stepp SD, Hallquist MN, et al. Attachment and social cognition in borderline personality disorder: specificity in relation to antisocial and avoidant personality disorders. Personal Disord. 2015;6(3):207-215.

82. Normann-Eide E, Johansen MS, Normann-Eide T, Egeland J, Wilberg T. Is low affect consciousness related to the severity of psychopathology? A cross-sectional study of patients with avoidant and borderline personality disorder. Compr Psychiatry. 2013;54(2):149-157.

83. Normann-Eide E, Johansen MS, Normann-Eide T, Egeland J, Wilberg T. Personality disorder and changes in affect consciousness: a 3-year follow-up study of patients with avoidant and borderline personality disorder. PLoS One. 2015;10(12).

84. Moroni F, Procacci M, Pellecchia G, et al. Mindreading dysfunction in avoidant personality disorder compared with other personality disorders. J Nerv Mental Dis. 2016;204(10):752-757.

85. Huprich SK. Malignant self-regard: a self-structure enhancing the understanding of masochistic, depressive, and vulnerably narcissistic personalities. Harv Rev Psychiatry. 2014;22(5):295-305.

86. Lengu KJ, Evich CD, Nelson SM, Huprich SK. Expanding the utility of the malignant self-regard construct. Psychiatr Res. 2015;229(3):801-808

87. Howe LC, Dweck CS. Changes in self-definition impede recovery from rejection. Pers Soc Psychol Bull. 2016;42(1):54-71.

88. Srivastava S, Tamir M, McGonigal KM, John OP, Gross JJ. The social costs of emotional suppression: a prospective study of the transition to college. J Personal Soc Psychol. 2009;96(4):883-897.

89. Tackman AM, Srivastava S. Social responses to expressive suppression: the role of personality judgments. J Pers Soc Psychol. 2016;110(4):574-591.

90. Gawda B, Bernacka R, Gawda A. The neural mechanisms underlying personality disorders. Neuroquantology. 2016;14(2):348-356.

91. Stravynski A, Elie R, Franche RL. Perception of early parenting by patients diagnosed avoidant personality disorder: a test of the overprotection hypothesis. Acta Psychiatr Scand. 1989;80(5):415-420.

92. Westermeyer J, Yoon G, Amundson C, Warwick M, Kuskowski MA Personality disorders in adopted versus non-adopted adults. Psychiatry Res. 2015;226(2-3):446-450.

93. Joyce PR, McKenzie JM, Luty SE, et al. Temperament, childhood environment and psychopathology as risk factors for avoidant and borderline personality disorders. Aust NZJ Psychiatry. 2003;37(6):756-764.

94. Hageman TK, Francis AJ, Field AM, Carr SN. Links between childhood experiences and avoidant personality disorder symptomatology. Int J Psychol Ther. 2015;15(1):101-116.

95. Rettew DC, Zanarini MC, Yen S, et al. Childhood antecedents of avoidant personality disorder: a retrospective study. $J$ Am Acad Child Adolesc Psychiatry. 2003;42(9):1122-1130.

96. Carr SN, Francis AJ. Do early maladaptive schemas mediate the relationship between childhood experiences and avoidant personality disorder features? A preliminary investigation in a non-clinical sample. Cogn Ther Res. 2010;34(4):343-358.

97. Crawford TN, Shaver PR, Cohen P, Pilkonis PA, Gillath O, Kasen S. Self-reported attachment, interpersonal aggression, and personality disorder in a prospective community sample of adolescents and adults. J Pers Disord. 2006;20(4):331-351.

98. Allen JP, Hauser ST, Borman-Spurrell E. Attachment theory as a framework for understanding sequelae of severe adolescent psychopathology: an 11-year follow-up study. J Consult Clin Psychol. 1996;64(2):254-263.

99. Fossati A, Krueger RF, Markon KE, Borroni S, Maffei C, Somma A. The DSM-5 alternative model of personality disorders from the perspective of adult attachment: a study in community-dwelling adults J Nerv Ment Dis. 2015;203(4):252-258.

100. Rettew DC, McKee L. Temperament and its role in developmental psychopathology. Harv Rev Psychiatry. 2005;13(1):14-27.
101. Brennan KA, Shaver PR. Attachment styles and personality disorders: their connections to each other and to parental divorce, parental death, and perceptions of parental caregiving. J Pers. 1998;66(5):835-878.

102. Bartholomew K. Avoidance of intimacy: an attachment perspective. J Soc Pers Relation. 1990;7:147-178.

103. Dickinson KA, Pincus AL. Interpersonal analysis of grandiose and vulnerable narcissism. J Pers Disord. 2003;17(3):188-207.

104. Fossati A, Feeney JA, Donati D, et al. Personality disorders and adult attachment dimensions in a mixed psychiatric sample: a multivariate study. J Nerv Ment Dis. 2003;191(1):30-37.

105. MacDonald K, Berlow R, Thomas ML. Attachment, affective temperament, and personality disorders: a study of their relationships in psychiatric outpatients. J Affect Disord. 2013;151(3):932-941.

106. Bowles DP, Meyer B. Attachment priming and avoidant personality features as predictors of social-evaluation biases. J Pers Disord. 2008;22(1):72-88.

107. Eikenaes I, Egeland J, Hummelen B, Wilberg T. Avoidant personality disorder versus social phobia: the significance of childhood neglect PLoS One. 2015;10(3): 0122846.

108. Allen JG, Coyne L, Huntoon J. Complex posttraumatic stress DISORDER in women from a psychometric perspective. $J$ Pers Assess. 1998;70(2):277-298.

109. Meyer B, Ajchenbrenner M, Bowles DP. Sensory sensitivity, attachment experiences, and rejection responses among adults with borderline and avoidant features. J Pers Disord. 2005;19(6): 641-658.

110. Strauss BM, Mestel R, Kirchmann HA. Changes of attachment status among women with personality disorders undergoing inpatient treatment. Couns Psychother Res. 2011;11(4):275-283.

111. Bartholomew K, Horowitz LM. Attachment styles among young adults: a test of a four-category model. J Pers Soc Psychol. 1991;61(2):226-244.

112. Nakash-Eisikovits O, Dutra L, Westen D. Relationship between attachment patterns and personality pathology in adolescents. $J$ Am Acad Child Adolesc Psychiatry. 2002;41(9):1111-1123.

113. Riggs SA, Paulson A, Tunnell E, Sahl G, Atkison H, Ross CA. Attachment, personality, and psychopathology among adult inpatients: selfreported romantic attachment style versus Adult Attachment Interview states of mind. Dev Psychopathol. 2007;19(1):263-291.

114. Lafreniere P. A functionalist perspective on social anxiety and avoidant personality disorder. Dev Psychopathol. 2009;21(4):1065-1082.

115. Beck A, Freeman A, Associates. Cognitive Therapy of Personality Disorders. New York, NY: The Guilford Press; 1990.

116. Meyer B, Carver CS. Negative childhood accounts, sensitivity, and pessimism: a study of avoidant personality disorder features in college students. J Pers Disord. 2000;14(3):233-248.

117. Eggum ND, Eisenberg N, Spinrad TL, et al. Predictors of withdrawal: possible precursors of avoidant personality disorder. Dev Psychopathol. 2009;21(3):815-838.

118. Griego J, Stewart SE, Coolidge FL. A convergent validity study of Cloninger's temperament and character inventory with the coolidge axis II inventory. J Pers Disord. 1999;13(3):257.

119. Coplan RJ, Wilson J, Frohlick SL, Zelenski J. A person-oriented analysis of behavioral inhibition and behavioral activation in children. Pers Indiv Diff. 2006;41(5):917-927.

120. Asendorpf JB. Abnormal shyness in children. J Child Psychol Psychiatry. 1993;34(7):1069-1083.

121. Gjerde L, Czajkowski N, Roysamb E, et al. The heritability of avoidant and dependent personality disorder assessed by personal interview and questionnaire. Acta Psychiatr Scand. 2012;126(6):448-457.

122. Drago A, Marogna C, Sogaard HJ. A review of characteristics and treatments of the Avoidant Personality Disorder. Could the DBT be an option? Int J Psychol Psychoanalysis. 2016;2(1):13.

123. Kamaradova D, Prasko J, Sandoval A, Latalova K. Therapeutic response to complex cognitive-behavioral and pharmacological treatment in patients with social phobia. Activ Nerv Super Rediviva. 2014;56(3-4):91-99. 
124. Hope DA, Herbert JD, White C. Diagnostic subtype, avoidant personality disorder, and efficacy of cognitive-behavioral group therapy for social phobia. Cognit Ther Res. 1995;19:399-417.

125. van Velzen CJ, Emmelkamp PM, Scholing A. The impact of personality disorders on behavioral treatment outcome for social phobia. Behav Res Ther: 1997;35:889-900.

126. Fava GA, Grandi S, Rafanelli C, Ruini C, Conti S, Belluardo P. Longterm outcome of social phobia treated by exposure. Psychol Med. 2001;31(5):899-905.

127. Alden L. Short-term structured treatment for avoidant personality disorder. J Consult Clin Psychol. 1989;57(6):756-764.

128. Eikenaes I, Gude T, Hoffart A. Integrated wilderness therapy for avoidant personality disorder. Nord J Psychiatry. 2006;60(4):275-281.

129. Feske U, Perry KJ, Chambless DL, Renneberg B, Goldstein AJ. Avoidant personality disorder as a predictor for treatment outcome among generalized social phobics. J Pers Disord. 1996;10:174-184.

130. Blanco C, Xu Y, Schneier FR, Okuda M, Liu SM, Heimberg RG. Predictors of persistence of social anxiety disorder: a national study. J Psychiatr Res. 2011;45(12):1557-1563.

131. Cox BJ, Turnbull DL, Robinson JA, Grant BF, Stein MB. The effect of avoidant personality disorder on the persistence of generalized social anxiety disorder in the general population: results from a longitudinal, nationally representative mental health survey. Depress Anxiety. 2011;28:250-255.

132. Huppert JD, Strunk DR, Ledley DR, Davidson JR, Foa EB. Generalized social anxiety disorder and avoidant personality disorder: Structural analysis and treatment outcome. Depress Anxiety. 2008;25(5):441-448.

133. Herpertz SC, Zanarini M, Schulz CS, et al. World Federation of Societies of Biological Psychiatry (WFSBP) guidelines for biological treatment of personality disorders. World J Biol Psychiatry. 2007;8(4):212-244.

134. Canton J, Scott KM, Glue P. Optimal treatment of social phobia: Systematic review and meta-analysis. Neuropsychiatr Dis Treat. 2012;8:203-215.

135. Ipser JC, Kariuki CM, Stein DJ. Pharmacotherapy for social anxiety disorder: a systematic review. Expert Rev Neurother. 2008;8(2):235-257.

136. Mayo-Wilson E, Dias S, Mavranezouli I, et al. Psychological and pharmacological interventions for social anxiety disorder in adults: a systematic review and network meta-analysis. Lancet Psychiatry. 2014;1(5):368-376.

137. Stein DJ, Ipser JC, Balkom AJ. Pharmacotherapy for social phobia. Cochrane Database Syst Rev. 2004;(4):CD001206.

138. Blanco C, Schneier FR, Schmidt A, et al. Pharmacological treatment of social anxiety disorder: a meta-analysis. Depress Anxiety. 2003;18(1):29-40.
139. Emmelkamp PM, Benner A, Kuipers A, Feiertag GA, Koster HC, van Apeldoorn FJ. Comparison of brief dynamic and cognitivebehavioural therapies in avoidant personality disorder. Br JPsychiatry. 2006;189:60-64.

140. Stravynski A, Belisle M, Marcouiller M, Lavallee YJ, Elie R. The treatment of avoidant personality disorder by social skills training in the clinic or in real-life setting. Can J Psychiatry. 1994;39:377-383.

141. Barber JP, Morse JQ, Krakauer ID, Chittams J, Crits-Christoph K. Change in obsessive-compulsive and avoidant personality disorders following time-limited supportive-expressive therapy. Psychotherapy. 1997;34:133-143.

142. Kvarstein EH, Arstein KV, Nordviste O, Dragland L, Wilberg T. Outpatient psychodynamic group psychotherapy - outcomes related to personality disorder, severity, age and gender. Personal Ment Health. 2017;11(1):37-50.

143. Balje A, Greeven A, van Giezen A, Korrelboom K, Arntz A, Spinhoven P. Group schema therapy versus group cognitive behavioral therapy for social anxiety disorder with comorbid avoidant personality disorder: study protocol for a randomized controlled trial. Trials. 2016;17.

144. Bamelis LL, Evers SM, Spinhoven P, Arntz A. Results of a multicenter randomized controlled trial of the clinical effectiveness of schema therapy for personality disorders. Am J Psychiatry. 2014;171(3): 305-322.

145. Chan CC, Bach PA, Bedwell JS. An integrative approach using thirdgeneration cognitive-behavioral therapies for avoidant personality disorder. Clin Case Stud. 2015:1-16.

146. Pos AE. Emotion focused therapy for avoidant personality disorder: pragmatic considerations for working with experientially avoidant clients. J Contem Psychother. 2014;44(2):127-139.

147. Price M, Tone EB, Anderson PL. Vigilant and avoidant attention biases as predictors of response to cognitive behavioral therapy for social phobia. Depress Anxiety. 2011;28(4):349-353.

148. Dimaggio G, D'Urzo M, Pasinetti M, et al. Metacognitive interpersonal therapy for co-occurrent avoidant personality disorder and substance abuse. J Clin Psychol. 2015;71(2):157-166.

149. HerbertJD, Gaudiano BA, RheingoldAA, Myers VH, Dalrymple K, Nolan EM. Social skills training augments the effectiveness of cognitive behavioral group therapy for social anxiety disorder. Behav Ther. 2005;36(2): 125-138.

150. Sheldon AE, West M. Attachment pathology and low social skills in avoidant personality disorder: an exploratory study. Can J Psychiatry. 1990;35(7):596-599.

151. American Psychiatric Association. Diagnostic and Statistical Manual for Mental Disorders (Third Edition). Washington, DC: American Psychiatric Association; 1980.
Psychology Research and Behavior Management

\section{Publish your work in this journal}

Psychology Research and Behavior Management is an international, peerreviewed, open access journal focusing on the science of psychology and its application in behavior management to develop improved outcomes in the clinical, educational, sports and business arenas. Specific topics covered in the journal include: Neuroscience, memory and decision making; Behavior
Dovepress

modification and management; Clinical applications; Business and sports performance management; Social and developmental studies; Animal studies. The manuscript management system is completely online and includes a very quick and fair peer-review system, which is all easy to use. Visit http://www. dovepress.com/testimonials.php to read real quotes from published authors. 